\title{
Run, Hide, Fight: Leveraging Academics to Enhance Emergency Preparedness Training for Active Shooter Events
}

\author{
Andrew S. Pyle \\ Clemson University \\ Clemson, SC USA \\ S. Paul Gennett \\ Clemson University \\ Clemson, SC USA \\ Darren L. Linvill \\ Clemson, SC USA
}

\begin{abstract}
College and university campuses are regularly faced with various types of crises. One category of crisis that is becoming a more regular event of concern is the active shooter event. Trainings exist that can help individuals respond more confidently in the event of an active shooter incident on campus. However, the authors were concerned that students with certain personality traits may be less likely to abide by active shooter training guidelines. We surveyed undergraduate students and compared the Big Five personality traits with perceptions of self and response efficacy related to the "Run, Hide, Fight" active shooter training video. Our findings confirm prior research findings and suggest a small, significant relationship between certain personality types and perceptions of efficacy.
\end{abstract}

Keywords - Active shooter, crisis, training, efficacy, emergency response

SUGGESTED CITATION: Pyle, A. S., Gennett, S. P., Linvill, D., L. (2019). Run, hide, fight: Leveraging Academics to enhance emergency preparedness traning for active shooter events. Proceedings of the International Crisis and Risk Communication Conference, Volume 2 (pp. 51-53). Orlando Fl: Nicholson School of Communication and Media. https://doi.org/10.30658/icrcc.2019.15

\section{INTRODUCTION}

On college campuses, students with diverse backgrounds and beliefs converge to live and learn. Colleges consistently face crises, from ethics violations such as grade tampering or administrative misconduct, to physical hazards such as fires and flooding (Mitroff, Diamond, \& Alpaslan, 2006). Meanwhile, low-probability, high-consequence events such as natural disasters and mass shootings are on the rise (Sellnow \& Seeger, 2013). In the wake of events like the Virginia Tech shooting, universities must prepare for the worst.

\section{LITERAURE REVIEW}

In response to the Columbine shooting of 1999 , the federal government now requires all institutions of higher education actively receiving federal funds to communicate a disaster plan to students. Most protocols mirror the official Department of Homeland Security instructions, which advocates for the linear thought process "Run, Hide, Fight." First, one should immediately evacuate in an active shooter situation. If evacuation is not possible, one should attempt to barricade oneself and avoid open areas. When one cannot run or hide, one should forcefully confront the shooter as a last resort. 
This study focuses on "Run, Hide, Fight" and the training video filmed by the City of Houston and the Ready Houston program (https://bit.ly/2K0ITgl). The six-minute video begins by referencing a series of sobering active shooter events before portraying an active shooting in an office. As the shooter moves throughout the building and shoots people with a shotgun, employees are forced to run, hide, and fight - in that order. This video constitutes a fear appeal, a "persuasive message designed to scare people by describing terrible things that will happen to them if they do not do what the message recommends" (Witte, 1992, p. 331).

\section{METHODS}

Ford and Frei (2016) found the Run, Hide, Fight message to be an effective training tool. Based on anecdotal evidence from the researchers' conversations with students, there was reason to believe the training may not be effective across all personality types. The researchers therefore conducted surveys structured as follows: participants completed a pre-test measure of the Big Five personality traits (John \& Srivastava, 1999), watched the Ready Houston video, then answered questions related to perceived efficacy of the message and intention to comply with the message developed by Xue, Hine, Marks, Phillips, Nunn, and Zhao (2016), based on Witte's extended parallel processing model (1992).

\section{RESULTS AND DISSCUSSION}

The results of the study confirmed Ford and Frei's findings. The study also confirmed the suppositions of the researchers and indicate further research is necessary to gain a more complete understanding of the student population. Students who are Agreeable and Open are more likely to find efficacy in the message. Neurotic students are more likely to have a high fear control response, while Open students tend to have low fear control. Conscientious students are more likely to have high danger control. Surprisingly, there were no significant differences based on respondents' sex (see table below). These findings offer important insight into how universities' emergency preparedness practitioners' approach active shooter training. Future research should expand the sample to other regions to increase sample diversity and expand understanding of the study context.

\begin{tabular}{|c|l|l|l|l|l|}
\hline & B & Std. Error & Beta & t & p \\
\hline & Efficacy & & & & \\
\hline Agreeableness & .083 & .030 & .169 & 2.77 & .006 \\
\hline Openness & .065 & .025 & .158 & 2.60 & .010 \\
\hline Adjusted R2 $=.055$ & & & & & \\
\hline & & & & & \\
\hline Neuroticism & Fear Control & & & & \\
\hline Adjusted R2 $=.017$ & .061 & .026 & .146 & 2.36 & .019 \\
\hline Conscientiousness & .074 & & & & \\
\hline Adjusted R2 $=.020$ & & .029 & .155 & 2.52 & .012 \\
& & & & & \\
\hline
\end{tabular}

\section{CONCLUSION}

Active shooter events will continue to be a challenge for college and university campuses. Scholars and practitioners have an opportunity to coordinate so that our campuses can be as prepared as possible for this type of event. By training and simulating these types of events, we can help prevent the kinds of in-the-moment freezing and confusion that can result in injuries and deaths.

\section{Author Biography}

Andrew S. Pyle earned his PhD in Communication at George Mason University. Pyle is an assistant professor in the Communication Department at Clemson University. mapyle@clemson.edu

S. Paul Gennett is earning his BS in Civil Engineering at Clemson University. sgennet@clemson.edu

Darren L. Linvill earned his $\mathrm{PhD}$ at Clemson University. Linvill is an associate professor in the Communication Department at Clemson University. 


\section{REFERENCES}

[1] Ford, J. L., \& Frei, S. S. (2016). Training for the unthinkable: Examining message characteristics on motivations to engage in an active-shooter response video. Communication Studies, 67, 438-454. https://doi.org/10.1080/10510974.2016.1196381

[2] John, O. P., \& Srivastava, S. (1999) The big five trait taxonomy: History, measurement, and theoretical perspectives (pp. 102-138). In Pervin, L.A. and John, O.P. Eds., Handbook of Personality: Theory and Research, Vol. 2, Guilford Press, New York.

[3] Mitroff, I. I., Diamond, M. A., \& Alpaslan, M. C. (2006). How prepared are America's colleges and universities for major crises?. Change: The Magazine of Higher Learning, 38, 61-67. https://doi.org/10.3200/CHNG.38.1.61-67

[4] Sellnow, T. L., \& Seeger, M. W. (2013). Theorizing crisis communication (Vol. 4). John Wiley \& Sons.

[5] Witte, K. (1992). Putting the fear back into fear appeals: The extended parallel process model. Communications Monographs, 59, 329-349. https://doi.org/10.1080/03637759209376276

[6] Xue, W., Hine, D. W., Marks, A. D., Phillips, W. J., Nunn, P., \& Zhao, S. (2016). Combining threat and efficacy messaging to increase public engagement with climate change in Beijing, China. Climatic change, 137, 43-55. https://doi.org/10.1007/s10584-016-1678-1 